\title{
Liquidity Effects of Listing Requirements
}

\author{
Sarah Draus ${ }^{1}$
}

May 2009

\begin{abstract}
I propose a model in which a stock exchange can improve its liquidity by tightening its listing requirements. Because these reduce information asymmetry, they increase the utility of investors and lead to a high investor participation on the exchange. However, the exchange never sets the highest possible level of listing requirements because investors also incur a risk due to more transparency. Their utility is concave in the level of listing requirements. This property determines the optimal decisions of an exchange as well as the social optimum. The level of listing requirements maximizing investor welfare depends on the sensitivity of the utility of investors to changes in liquidity and varies with the organization of listing and trading. A monopolist exchange always under-regulates if regulation is costly. Underregulation is exacerbated if other trading venues free ride on the regulation and if the trading fee is determined by the level of listing requirements. While investors are better off if trading is separated from listing and is a competitive industry, an exchange has a higher profit when it is a monopolist in listing and trading.
\end{abstract}

Keywords: liquidity, competition, trading volume, regulation, stock exchanges

EFMA classification codes: $360,530,540,750$

\footnotetext{
${ }^{1}$ Université Paris Dauphine, Place du Maréchal de Lattre de Tassigny, 75016 Paris, France DRM - Finance - sarah.draus@ dauphine.fr

Tel: + 33 (0)1 440542 57, Fax: + 33 (0)1 44054023

I am grateful for many helpful comments from Thierry Foucault, Denis Gromb and Terrence Hendershott.
} 


\section{Liquidity Effects of Listing Requirements}

\section{Introduction}

Recent changes in the industrial organization of stock exchanges have given rise to a debate in the academic and professional literature about how exchanges should be regulated. ${ }^{2}$ Exchanges are increasingly turned into listed and profit maximizing entities. They also compete with other trading venues for volume on the secondary market, which decouples listings from trading. If exchanges regulate listings, competing trading platforms can free ride on this regulatory activity while offering more advantageous trading conditions. These developments in the stock market industry have given rise to a debate upon whether stock markets should continue to regulate listings or whether they should focus on offering a cheap and liquid trading venue while other institutions deal with listings.

This paper explores how a separation of listing and trading affects the optimal decisions upon trading fees and listing requirements by profit maximizing exchanges, and the impact of such a separation on investor welfare. It shows that listing requirements have an impact on liquidity through less information asymmetry and enhanced investor participation. These liquidity effects are shown to determine the decisions of exchanges in equilibrium, and the welfare effects of different trading and listing organizations. The specific questions addressed in this paper are: what determines the profit and thus the equilibrium decisions of exchanges, what determines the socially optimal level of listing requirements, what drives possible under-regulation?

Investors benefit from a higher level of listing requirements through a better liquidity on the market. However, what listing requirements maximize their welfare depends on the sensitivity of their utility to changes in liquidity. This sensitivity is determined by the risk premium but also by the trading fee. The higher the trading fee is, the less investors benefit from higher listing requirements and the smaller is the socially optimal level of listing requirements. Trading fees are influenced by the industrial organization of trading and listing which affects therefore also the regulation maximizing investor welfare. Investors are best-off and require a high level of listing requirements when the trading fee is the lowest.

As long as an exchange bears regulatory costs, it under-regulates regardless of how listing and trading are organized. The extent of under-regulation depends on the sensitivity of the exchange's income to changes in the liquidity. Under-regulation is exacerbated by two

\footnotetext{
2 Fleckner (2006), Macey and O’Hara (2005), Macey and O’Hara (2002), Kuan and Diamond (2006), Lee (2002), Steil (2002), Centre for financial market integrity (2007), OICV - IOSCO Consultation Report (2006)
} 
factors. First, if the volume goes on another trading venue which free rides on the regulatory activity of the exchange, the latter has a smaller income and sets a smaller listing requirement. Second, if trading is organized by a monopoly, the trading fee increases with the level of listing requirements. This reduces the impact of improved liquidity on the exchange's profit and induces the exchange to set a low listing requirement. Both effects can be avoided by introducing competition in trading in which case, the liquidity effects of listing requirements have the highest impact on investor welfare.

The main elements of the model are as follows. Investors can enter a stock exchange and participate in the IPO of a firm. They do so if their expected utility exceeds opportunity costs which differ across them. Those investors that have entered the exchange can be hit by a liquidity shock in which case they must sell their holding. They can have the possibility to switch to a trading platform which offers a smaller trading fee. The listed firm must disclose information about its productivity. The precision of this information depends on the level of listing requirements. The shareholders of the firm only observe the information released by the firm. However, there are informed investors on the secondary market knowing perfectly the productivity of the firm. Their existence gives rise to a spread. The exchange sets its trading fee as well as its listing requirements to maximize its expected profit. A benchmark case is developed in which the monopolist exchange lists the firm and organizes trading in the shares. The results are compared to cases in which listing is separated from trading.

The spread is determined by the probability of informed trading on the secondary market. Therefore it decreases not only the smaller information asymmetry is, but also the more uninformed investors enter the exchange. A smaller information asymmetry increases the expected utility from participating in the IPO which attracts investors with high opportunity costs on the exchange, reducing further the spread. Two equilibria are possible: If the exchange sets a high level of listing requirements, investor participation is high leading to a high market capitalization, a high volume and a good liquidity. If the level of listing requirements is low, market participation is small leading to a small volume and a bad liquidity.

Multiple equilibria due to investor participation externalities have been extensively analyzed in Dow (2004) and Pagano (1989) in a slightly different context. In these models, uninformed investors trade on the stock market to hedge endowment shocks. The more investors participate on the stock exchange, the better is liquidity, either because informed trading is reduced (Dow 2004) or because prices become less sensitive to individual endowment shocks (Pagano 1989). While their models focus on the entry decision of 
investors and ignore the organization of the exchange, this paper pushes the analysis further since it integrates insights of Dow (2004) into a context of exchange competition. The present paper also contributes to this literature because it not only states the possibility of several equilibria, but endogenises their occurrence. It shows also that the existence of several equilibria may incite the exchange to implement an equilibrium with a small investor participation and a too low level of listing requirements compared to the one maximizing investor welfare, even if regulatory costs are small.

Investors' utility does not increase monotonically in the level of listing requirements on the exchange. Investors may need to trade on the secondary market after information is revealed and incur therefore a risk related to the precision of information. The more precise information is the higher is the uncertainty about the future price on the secondary market. If this "signal risk" (Alles and Lundholm 1993) is important, it may offset the benefit of smaller trading costs if the precision is high. Thus utility of investors is concave in the precision of information and can decrease for high levels of precision. This limits the socially optimal level of listing requirements which decreases, the smaller the gains from a better liquidity are compared to the signal risk. This property of the utility function is studied in Diamond (1985) who shows that as long as more precise information reduces the number of investors searching for costly information, a high precision increases investor welfare by reducing information costs and making beliefs more homogenous. In the model analyzed here, the concave utility is obtained with identical preferences and homogeneous beliefs. It stems from the trade-off investors face between a better liquidity and a high signal risk.

The concave utility also influences the optimal level of listing requirements set by the exchange. The higher the information precision is, the smaller is the increase in the exchanges income. This is because the volume as well as the market capitalization are determined by investors preferences. This prevents the exchange from setting a high enough level of listing requirements to maximize investor welfare. This result complements findings in Chemmanur and Fulghieri (2006) and Huddart et al. (1999) who show that a monopolistic exchange optimally sets the highest possible level of listing requirements. In Huddart et al. in particular, the listing requirements aim precisely at reducing informed trading as in the model analyzed here. However, in their model investors benefit always from a more precise information and the signal risk stemming from the fact that investors determine their optimal portfolio before information is released but expect to trade after information is released, does not exist. This risk, however, is shown to influence investor's preferences and behavior and thereby the trading conditions, in particular the liquidity, in equilibrium. 
If the exchange is a monopolist, its income stems from a listing fee corresponding to the market capitalization of the listed firms and from the trading volume. The optimal trading fee increases the smaller the listing requirement is but total trading costs diminish. The exchange implements the equilibrium in which all investors enter if its income is sensitive enough to changes in the liquidity. Otherwise, the exchange sets a low level of listing requirement and excludes high cost investors. The exchange under-regulates always, but this is only due to the existence of regulatory costs. Also, the existence of a trading fee lowers the sensitivity of the income to changes in the liquidity which increases the under-regulation problem.

If listing is separate from trading and if trading is organized by another monopolist, the trading platform can free ride on the listing requirements set by the exchange and offer a good liquidity. This, however, induces the trading platform to set a high trading fee. The trading fee lowers the market capitalization of the listed firms and thereby the profit of the exchange. The trading platform does not internalize the loss of the regulating exchange due to the trading fee which is therefore higher than in the case of a single monopolist exchange. The exchange sets a low level of listing requirements not only because it loses income from trading but also because of the higher trading fee. In this case, investors are worse-off and the under-regulation problem is more severe than in the benchmark case.

The free riding problem is not the source of under-regulation but enforces it. As long as the trading fee depends on the level of listing requirements, it always lowers the effect of a better liquidity on investor welfare and increases under-regulation. If listing is separated from trading and the trading industry is competitive, there is no free riding problem and no interdependence between the trading fee and the listing requirements. In this case, investor welfare is the highest. However, the profit of the exchange is smaller than in the benchmark case. The higher income from listings does not compensate the loss of income from trading. There is a divergence in interests since investors prefer separation with a competitive trading industry whereas the exchange prefers to be a monopolist in listing and trading.

Listing requirements are shown to improve liquidity by diminishing information asymmetry, as well as by entailing more participation of investors. Both of these results grounding the analysis of the model find support in the empirical literature. Frost et al. (2002) show that the strength of disclosure systems is positively associated with market liquidity in a sample of 50 stock exchanges in the world. Ramadorai and Jenkinson (2007), suggest that there are different clienteles among investors with respect to listing requirements. While investors may prefer a highly regulated exchange for confidence reasons (a smaller 
probability to be cheated by the firms, a higher average quality and a smaller maximum risk of listed firms $)^{3}$, the analysis here links investors participation to a smaller risk of adverse selection on the secondary market. It takes the perspective of Huddart et al. (1999), who conclude that a profit maximizing monopolist exchange sets a high level of listing requirements to attract the order flow of liquidity traders, but broadens the analysis by introducing competition for volume by another trading venue in the shares listed on the exchange $^{4}$ as well as heterogeneity among investors. These enlargements allow a more realistic approach concerning listing regulation and show that the optimal result in Huddart et al. (1999) is only one among several possible equilibria and tightly linked to market conditions not taken into account in their model.

The article is organized as follows. Section 2 sets out the model. Section 3 analyses the entry decision of investors. Section 4 presents the optimal trading fee and listing requirement set by a monopolist exchange. Section 5 discusses separation of listing and trading and section 7 concludes. Proofs are given in the appendix.

\section{Model}

Firm. Consider a firm with a risk neutral manager and without assets in place. The firm can realize a project if it raises capital by listing on an exchange and issuing $\mathrm{K}$ shares. If the firm does not list, it cannot realize the project and its value is zero. ${ }^{5}$ The project yields a payoff of $V=1+x$ per share. The productivity, $x$, is a random variable distributed over four equally likely states of the nature. In the two best states, the average productivity is $\bar{x}_{h}$ and the final productivity can take the values $\bar{x}_{h}+\sigma$ or $\bar{x}_{h}-\sigma$ with probability $1 / 2$. In the two other states, the average productivity is $\bar{x}_{l}$, with $\bar{x}_{h}>\bar{x}_{l}>0$, and the final productivity can take the values $\bar{x}_{l}+\sigma$ and $\bar{x}_{l}-\sigma$ with probability $1 / 2$. Average productivities represent the quality of the firm. A good firm has a high mean productivity. The parameter $\sigma$ represents the risk of the firm related to its economic activity. The difference in average productivities is assumed to be high relative to the economic risk: $\bar{x}_{h}-\bar{x}_{l}>2 \sigma$.

\footnotetext{
${ }^{3}$ See for instance Guiso et al. (2008), and Easley and O'Hara (2007)

${ }^{4}$ Huddart et al. (1999) determine the optimal listing requirement by introducing competition in listings. Firms listing on an exchange with a small level of listing requirements have less liquid shares since investors face more informed trading.

${ }^{5}$ If the firm could realise the project with other means, it would suffer a positive opportunity cost if listing. The firm lists as long as this opportunity cost is not larger than the expected gain from listing. Since this paper focuses on investors' decisions and not listing decisions this possibility is omitted for simplicity. Adding it would not change the result.
} 
Figure 1: payoff of the asset

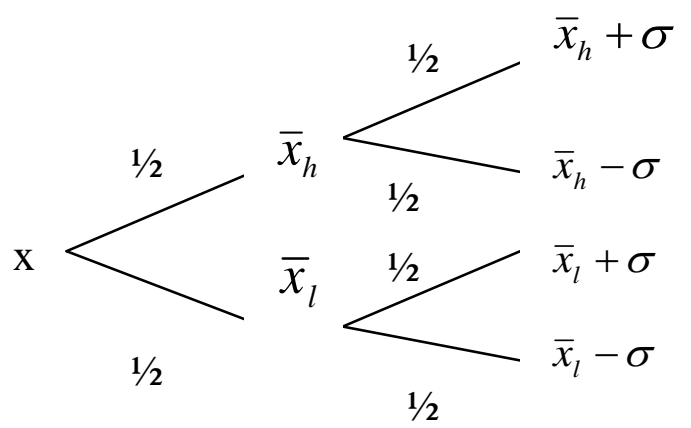

At the time of listing, the average productivity is unknown to all agents. Therefore, the listing decision alone does not convey information to the market about the quality of the firm. ${ }^{6}$ The expected market value of the firm if it lists is positive and since the reservation value is zero, the firm always lists.

The manager learns its type after listing. However, he cannot or is not willing to credibly convey this information to market participants. It remains his private information. Even though, in reality, firms voluntarily disclose information, and in particular large firms are followed by analysts and the media, there is information asymmetry even about large international firms. This model relies on the existence of information asymmetry, and needs therefore this hypothesis. If the manager could disclose credibly its type, a good manager would always do so. Since the market expects the good manager to disclose, it infers that a firm which does not disclose is bad and information asymmetry vanishes. Besides this theoretical argument, two "practical" reasons justify this assumption. First, this paper ignores completely competition on the product market. Literature in accounting ${ }^{7}$ shows that firms may suffer "proprietary costs" by disclosing information to competitors. These may adjust their strategies and compete more aggressively on the product market, which can lead to a lower profit of the firm considered if it discloses information about its type. Second, for medium size firms and firms with weak media or analysts' coverage it may be difficult and costly to bring the information to all market participants without an institutionalized procedure.

Exchange. There is an exchange listing the firm and organizing trading in the shares. It is a monopolist in listing as well as in trading. The exchange charges a trading fee, c, per share traded on the secondary market and a listing fee, F, paid by the firm. The listing fee is a

\footnotetext{
${ }^{6}$ In a similar set up in which the firm knows its type before it takes the decision to list, Stoughton et al. (2001) show the existence of separating equilibria in which only good firms list and reveal perfectly their type. More generally, as long as the listing decision leads to semi-separating equilibria, it reveals the distribution of the types of listed firms. The results in this paper rely on the existence of information asymmetry and would also hold if listing was informative as long as it is not perfectly revealing.

${ }^{7}$ Nichols and Street (2007), Leuz (2004), Verrecchia $(1983,2001)$
} 
fixed price corresponding to the market value of the firm. If the listing fee varied with the amount of issued shares or with the market value of the firm, the number of issued shares and the market value would always be smaller than in the case of a fixed fee. Therefore, a variable listing fee is not optimal for the exchange.

The exchange also sets listing requirements. Listing requirements are a set of rules to which the listed firm must commit. These rules may contain accounting and reporting standards but also corporate governance devices which, if they are in place, may reveal information about the quality of the firm. Listing requirements lead to public information about the quality of the firm once the latter has been revealed to the manager. They constitute a noisy public signal, s, observed by all market participants. Since the type of the firm is unknown when the firm lists and both possible qualities occur with the same probability, the signal is expected to take either value, $\bar{x}_{h}$ or $\bar{x}_{l}$, with probability $1 / 2$ when the firm lists.

With probability $p \in(0.5,1)$ the observed signal corresponds to the true type of the firm; it corresponds to the wrong type otherwise. The precision of the signal, $p$, represents the strictness of the listing requirements: the tougher they are, the higher is the probability that the observed signal corresponds to the true type of the firm. The exchange bears regulatory costs related to the enforcement of the listing requirements: $C(p)$ with $C^{\prime}>0$ and $C^{\prime \prime}>0$. The firm does not bear compliance costs.

The set up of this game is close to Staughton et al (2001) but differs along two dimensions. First the timing of information revelation is different since in Staughton et al. the manager knows its type (which is also the average payoff) before he lists the firm (see footnote 8). Second the information content is not the same. In Staughton et al. the signal is noisy information about the final payoff of the security, while in the present model the signal reveals information about the average payoff of the security. Both types of information lead to less adverse selection on the exchange, but their impact on the risk perceived by investors is different. While a signal on the final payoff reduces the potential variability of this payoff once information has been revealed, information about the average quality of the firm reduces only the uncertainty on the distribution mean of the payoff but not the ex post perceived risk of the economic activity of the firm. This distinction allows separating the effects of the risk of the economic activity and the effects of the uncertainty about the firms' quality, on the decisions of the exchange. The assumption about the information content of the signal seems also consistent with reality since information reported by or about firms concerns items like production procedures, economic achievements, planned investments or, through the 
application of corporate governance devices, the likelihood of private benefit extraction or non optimal investment strategies in the perspective of investors (empire building...). This information allows assessing the quality on average of firms.

The exchange sets the trading fee, $\mathrm{c}$, the listing fee, $\mathrm{F}$, and the level of listing requirements, p, to maximize its expected profit, П. As exchanges are increasingly turned into demutualised and listed entities, this objective seems the must accurate in the current context. $^{8}$

Investors. There are two types of investors on the exchange: informed and uninformed. The number of informed investors is $N_{I}$. They know perfectly the quality of the firm and trade only on the secondary market in the case the listed firm is bad. Uninformed investors observe the signal, s. They are the only investors participating in the IPO. When uninformed investors enter the stock market, they bear opportunity costs: $N_{l}$ among them have low opportunity costs $\left(O c_{l}\right)$ and $N_{h}$ have high opportunity costs $\left(O c_{h}\right)$, with $O c_{h}>O c_{l}>0 .{ }^{9}$ Opportunity costs may represent alternative investment opportunities. They may also represent entry costs borne by investors such as costs related to information gathering and understanding. Christiansen et al. (2005), for example, find that economists are more likely to participate in the stock market than persons with any other education.

If uninformed investors have entered the stock market and bought shares of the firm, they may be hit by a liquidity shock: with probability $t \in(0,1)$ they must sell their entire holding on the secondary market. This constitutes the trading volume of the exchange. In the case of a liquidity shock, investors sell their holding to a risk neutral market maker. Informed traders may mimic uninformed ones if they know that the firm is bad. The market maker has the same information as uninformed investors. The price, at which he is willing to buy the shares, $\mathrm{P}$, takes into account the possibility that the order comes from an informed investor. Thus the market maker sets a spread, $\mathrm{S}$, due to information asymmetry.

Uninformed investors are risk averse. They have an initial wealth, $W_{0}$, and determine their demand of shares, $D^{*}$, by maximizing the mean-variance expected utility of their future wealth, $\tilde{W}$ :

$$
\underset{D}{\operatorname{Max}} E[\tilde{W}]-\frac{b}{2} \operatorname{Var}(\tilde{W})
$$

\footnotetext{
${ }^{8}$ According to the 2006 cost and revenue study by the World Federation of Exchanges, 75\% of members which responded to the survey were for-profit organizations in 2006.

${ }^{9}$ This modelling device is also used in Pagano (1989).
} 
Investors enter the stock market if their expected utility is higher than their opportunity cost. Denote the number of uninformed investors entering the stock market by $N_{u}$. The fraction of informed investors among all investors on the market is $n=N_{I} /\left(N_{u}+N_{I}\right)$.

Timing. The game is organized in five periods. In the two first periods, the exchange determines its organization: first it sets a level of listing requirements (this decision is considered as a long term decision since it implies to set up particular listing procedures as well as specialized departments to enforce these requirements), second the exchange sets a trading fee. The listing fee is the market capitalization of the firms and thus not determined separately by the exchange. However, it is implicitly taken into account in the determination of $\mathrm{p}$ and $\mathrm{c}$. In the third period, investors decide whether to enter the stock market, and if they do, they buy the shares issued by the firm. The firm determines how many shares to issue. In the fourth period, the manager of the firm learns its type and the signal, $\mathrm{s}$, is revealed to the market due to compliance with listing requirements. In the fifth period, some uninformed investors are hit by a liquidity shock and sell their holing to a market maker. Finally, in the last period payoffs are realized. The model is solved backwards, beginning with the bid price set by the market maker in period 5 and ending with the determination of the level of listing requirements in period one. Figure 2 displays the different stages of the model.

\section{Investors' entry decision}

Trading. The following trading model draws upon Glosten and Milgrom (1985) and is a generalization of Dow (2004) to a situation with a public signal. Only one side of the market is modeled to determine the bid price: the transaction between the selling investors and the market maker. The spread is inferred from the difference between the bid price and the conditional expected value of the asset. As in Dow (2004), it corresponds to twice this difference.

When the market maker receives a sell order, he determines the bid price, $\mathrm{P}$, according to the signal, s, its precision, $\mathrm{p}$, as well as the different types of investors on the market. Depending on the observed signal, the probability that the order stems from an uninformed investor differs.

If the market maker has observed $s=\bar{x}_{h}$, with probability $\mathrm{p}$ the signal corresponds to the true type of the firm and the order comes from an uninformed investor since an informed one does not sell the shares of a good firm. With probability (1-p) the signal is wrong and the probability that the order comes from an uninformed investor is $(1-n) t$. Otherwise, the order 
stems from an informed investor. The market maker sets the bid price per share conditional on the good signal, $P_{s=\bar{x}_{h}}$, such as to break even:

$$
P_{s=\bar{x}_{h}}=V_{x=\bar{x}_{l}}+(p+(1-p)(1-n) t)\left(E\left[V \mid s=\bar{x}_{h}\right]-V_{x=\bar{x}_{l}}\right)
$$

with $E\left[V \mid s=\bar{x}_{h}\right]=p\left(1+\bar{x}_{h}\right)+(1-p)\left(1+\bar{x}_{l}\right)$, the expected value of the asset conditional on the signal $s=\bar{x}_{h}$ and $V_{x=\bar{x}_{l}}=1+\bar{x}_{l}$ the value of the asset of a bad firm. The corresponding spread is:

$$
S_{s=\bar{x}_{h}}=2\left(E\left[V \mid s=\bar{x}_{h}\right]-P_{s=\bar{x}_{h}}\right)=2(1-p)(1-(1-n) t) p \Delta x
$$

with $(1-p)(1-(1-n) t)$ the probability of an informed trade and $p \Delta x$ the difference in value between the conditional expectation and the low quality firm.

If the market maker has observed $s=\bar{x}_{l}$, with probability (1-p) the signal is wrong and the order comes from an uninformed investor. With probability $\mathrm{p}$, the signal is correct and the order comes from an uninformed investor with probability $(1-n) t$ and from an informed investor otherwise. The bid price set by the market maker given the bad signal, $P_{s=\bar{x}_{l}}$, is:

$$
P_{s=\bar{x}_{l}}=V_{x=\bar{x}_{l}}+((1-p)+p(1-n) t)\left[E\left(V \mid s=\bar{x}_{l}\right)-V_{x=\bar{x}_{l}}\right]
$$

with $E\left(V \mid s=\bar{x}_{l}\right)=p\left(1+\bar{x}_{l}\right)+(1-p)\left(1+\bar{x}_{h}\right)$, the expected value of the asset conditional on the signal $s=\bar{x}_{l}$. The corresponding spread is:

$$
S_{s=\bar{x}_{l}}=2\left(E\left[V \mid s=\bar{x}_{l}\right]-P_{s=\bar{x}_{l}}\right)=2 p(1-(1-n) t)(1-p) \Delta x
$$

with $p(1-(1-n) t)$ the probability of an informed trade and $(1-p) \Delta x$ the difference in value between the conditional expectation and the low quality firm.

Although the probability of informed trading is smaller in the case of a good signal, the market maker reduces the bid price by a higher amount which increases the spread. On the contrary, if the signal is bad, the amount by which the price is reduced compared to the 
expectation is smaller which reduces the spread despite a higher probability of informed trading. These two effects offset each other. The spread is the same regardless of whether the signal is good or bad: $S_{s=\bar{x}_{h}}=S_{s=\bar{x}_{l}}$.

Investors determine their holding in the third period, before the signal is released. Because of the possibility of informed trading, uninformed investors expect the market maker to set a spread and to sell their order at a discount relative to the unconditional expected payoff. However, only the bid price is a random variable for investors. The spread is twice the distance between the unconditional expected value of the asset, $E[V]=0.5\left(2+\bar{x}_{l}+\bar{x}_{h}\right)$, and the expected bid price, $E[P]$ :

$$
S=2(E[V]-E[P])=2(1-p) p(1-(1-n) t)\left(\bar{x}_{h}-\bar{x}_{l}\right)
$$

In the third period, the bid price is a random variable since it depends on the realization of the signal and the resulting probability of informed trading. Thus, investors incur a risk when buying the security which is related to how the future realization of the signal impacts the bid price. Information revelation shifts wealth of investors either upwards or downwards (relative to prior expectation). This risk is labeled "signal risk" in Alles and Lundholm $(1993)^{10}$ and is determined here by the variance of $\mathrm{P}$ :

$$
\operatorname{Var}(P)=\frac{1}{4}(1-2 p)^{2}\left(\bar{x}_{h}-\bar{x}_{l}\right)^{2}
$$

The more precise this signal is, the smaller is the spread but the closer is the revised expectation to the true the two possible values, $\bar{x}_{h}$ and $\bar{x}_{l}$, which creates more volatility in the price. If investors sell after a good signal, they experience a utility gain. If however they sell after a bad signal, they suffer a utility loss. The variability of the bid price increases the more precise the signal is. It is also amplified by the difference in average productivities since the randomness of the bid price stems from the uncertainty about average quality and not from the firms' economic risk $(\sigma)$. The signal risk is only induced by the early partial resolution of uncertainty. Ceteris paribus, investors would prefer the firm not to commit to disclose information. In the case of a completely uninformative signal $(\mathrm{p}=0.5)$, the trading price and the spread are only affected by the proportion of informed investors among all market

\footnotetext{
${ }^{10}$ It is also called "distributive risk" by Hirshleiffer (1971).
} 
participants, which is known. In this case, there is no uncertainty on the bid price $(\operatorname{Var}(P)=0)$, but the spread is the highest possible (for a given number of investors), $S=0.5(1-(1-n) t)\left(\bar{x}_{h}-\bar{x}_{l}\right)$.

IPO. Investors participating in the IPO determine their demand of the asset by maximizing the expected utility of their final wealth. Since the price on the secondary market is random, investors face six states of the world at this stage. If they keep their holding until the end of the game (which occurs with probability (1-t)), their final wealth is determined by the four states described in figure 1. If investors must sell their holding before the end of the game (which occurs with probability $\mathrm{t}$ ), they face two additional sates of the nature since the bid price can be either high or low, depending on the signal.

The final wealth differs depending on whether investors are hit by a liquidity shock. In the case, they keep their holding until the end of the game, investors receive the final payoff and their final wealth is: $\tilde{W}=D^{*}\left(V-P_{I P O}\right)+W_{0}$. If investors have to sell their holding in the fourth period, their final wealth depends on the bid price they obtain: $\tilde{W}=D^{*}\left(P-c-P_{I P O}\right)+W_{0}$. When investors determine their portfolio holding, they take the expectation over the period of holding and over the values of the asset:

$$
E[\tilde{W}]=W_{0}+D^{*}\left(E[V]-t(S / 2-c)-P_{I P O}\right)
$$

Ceteris paribus, the expected wealth increases the more precise information is because it depends only on the spread which diminishes with $\mathrm{p}$. The effect of the precision of the signal on the variance of the final wealth is ambiguous. The precision increases the volatility of the price but decreases the spread, reducing thereby the wealth loss due to trading. The signal has no impact on the economic risk of the firm.

\section{Lemma 1}

Investors face three types of risks:

(i) a "fundamental risk" due to the variability of the expected payoff: $(1-t) \operatorname{Var}(V)$

(ii) a "signal risk" due to the uncertainty on the bid price: $\operatorname{Var}(P)$

(iii) a "horizon risk" due to the uncertainty about how long investors can keep their holding: $L R=\left(\frac{E(S)}{2}+c\right)^{2}(1-t) t$ 
Investors incur a fundamental risk if they keep the asset until the payoff is realized. This risk is not only determined by the risk of the economic activity $\left(\sigma^{2}\right)$, but also by the uncertainty about the quality of the firm. Since the investment decision is taken before the realization of the signal, this risk is not affected by its precision. However, after public information is revealed, this risk diminishes since uncertainty on the firm's quality is smaller. However, the price shifts together with beliefs, which are homogenous, so that there is no trading once the signal is observed and investors keep their initial holding if they are not hit by a liquidity shock.

In addition to the fundamental and the signal risk, investors also incur a risk related to the uncertainty about how long they can keep the asset since expected payoffs differ in all six states of the nature (horizon risk). Investors cannot insure against the liquidity shock. Their horizon risk is not diversifiable. The signal risk and the horizon risk are affected in opposite ways by the precision of information. The horizon risk is determined by the difference between the expected payoff of the security and the expected bid price. This difference corresponds to the trading costs which diminish the higher the precision is, ceteris paribus, since the spread becomes smaller. Thus, while the signal risk always increases with $\mathrm{p}$, the horizon risk always decreases with $\mathrm{p}$. The realization of an informative signal can increase as well as decrease investors' utility depending on which of the two risks takes the overhand.

Investors determine the price they are willing to pay per share by maximizing the utility of their final wealth. They discount the share price, $P_{I P O}$, with respect to the three types of risks they face and the expected trading costs (the spread and the trading fee): $P_{I P O}=E[V]-t(S / 2-c)-\frac{b((1-t) \operatorname{Var}(V)+t \operatorname{Var}(P)+L R)}{N_{u}} K$. This represents a cost for the firm which adjusts the amount of issued shares. The firm issues the number of shares, $\mathrm{K}$, maximizing its expected market value: $\operatorname{Max}_{K} P_{I P O} K$. In equilibrium, the number of issued shares is:

$$
K^{*}=\left[E[V]-t\left(\frac{S}{2}+c\right)\right] \frac{N_{u}}{2 b((1-t) \operatorname{Var}(V)+t \operatorname{Var}(P)+L R)}
$$

Whether the number of issued shares increases with the precision of information depends on the effect of the latter on the investors' risk. However, the firm always benefits from a more horizon market since liquidity reduces the trading costs and thereby also the liquidity risk of investors. The more uninformed investors participate in the exchange, the less 
the firms' decision is affected by the risk of investors' final wealth since the latter can be spread over a higher number of investors. In this case, the amount of issued shares becomes more sensitive to changes in trading costs. Thus the higher the number of participating investors is, the more shares are issued for a given signal precision.

The resulting equilibrium share price and individual demand of investors are as follows:

$$
\begin{aligned}
& P_{I P O}^{*}=\frac{1}{2}\left(E[V]-t\left(\frac{S}{2}+c\right)\right) \\
& D^{*}=\frac{P_{I P O}^{*}}{b((1-t) \operatorname{Var}(V)+t \operatorname{Var}(P)+L R)}
\end{aligned}
$$

The equilibrium price at the IPO does not depend on the risk premium of investors since the firm adjusts the size of the share issue to it. The IPO price increases monotonically with the precision of the signal because it depends only on trading costs. Thus, the more precise public information in the future leads always to higher share prices, but not necessarily to higher number of issued shares in equilibrium.

The precision of information has two opposite effects on the demand of investors. On the one hand, it decreases the spread and thereby investors' trading cost as well as their horizon risk. On the other hand, it increases their signal risk. For small precisions, the signal risk is small and an increase in the precision of information also increases the optimal demand of investors. In this case, investors benefit from a better liquidity. If, however, the precision is high, changes in the signal risk have a higher impact on the equilibrium demand than the better liquidity. In this case, an increase in the precision reduces the equilibrium demand. ${ }^{11}$

\section{Proposition 1:}

The expected utility of investors is concave in the precision, $\mathrm{p}$, in equilibrium. If the signal risk faced by investors is large enough, $E U[\tilde{W}] *$ decreases for high levels of p.

$$
E U[\tilde{W}]^{*}=W_{0}+\frac{P_{I P O}^{*}{ }^{2}}{2 b((1-t) \operatorname{Var}(V)+t \operatorname{Var}(P)+L R)}
$$

\footnotetext{
${ }^{11}$ There is a signal $p_{D}^{*} \in(0.5,1)$ for which $\frac{\partial D^{*}}{\partial p}=0$ if the following condition holds: $P_{I P O}^{*}=((1-t) \operatorname{Var}(V)+t \operatorname{Var}(P)+L R)\left(\frac{4 \Delta x}{1-(1-n) t}-2(1-t)\right)^{-1}=A$. The demand $D^{*}$ increases in $\mathrm{p}$ if $P_{I P O}^{*}<A$ and decreases otherwise. Since $\frac{\partial P_{I P O}^{*}}{\partial p}>0$ and $\frac{\partial A}{\partial p}<0$, the equilibrium demand is increasing for $p<p_{D}^{*}$ and decreasing for $p>p_{D}^{*}$
} 
Similarly to the optimal demand, the precision of the signal has opposite impacts on the equilibrium expected utility. Whether the utility of investors increases in p depends on how important the signal risk is. When $\mathrm{p}$ is small, the signal risk is small but trading costs are high. This keeps not only the expected wealth of investors small, but lowers also their utility through a high horizon risk. An increasing precision lowers trading costs and thus the liquidity risk, but increases the signal risk. Investors' utility is maximized for the level of $\mathrm{p}$ at which these two effects exactly offset. High levels of precision tend to make investors worse off despite the better liquidity on the exchange resulting in less adverse selection and a smaller horizon risk, because they exacerbate the uncertainty about the payoff in the case of a liquidity shock. Since all investors have the same preferences and beliefs, more precise public information increases investor welfare up to a certain precision level. Very informative information can be undesirable for investors.

The fact that more public information does not necessarily increase the ex ante welfare of investors has been stated in several papers in the accounting literature. Hakansson et al. (1982) determine under which conditions information is welfare improving. Diamond (1985) shows that the ex ante utility of investors is concave in the precision. His argument is related to information production. A firm optimally releases public information with a high enough precision for investors not to engage in costly information production. This saves information costs and improves risk sharing by making beliefs more homogenous. However Alles and Lundholm (1993) show that this result is strongly linked to the assumption that private signals are independent. While many papers in the mentioned literature conclude that investors must either differ in preferences or have heterogeneous beliefs for information to have social value, my model assumes investors with identical utilities and homogenous beliefs and yet their utility is concave in the precision. This is because the precision of public information affects the trading conditions on the market and thereby not only the trading costs borne by investors but also their risk. ${ }^{12}$

Not only does the individual utility of investors depend on the trading conditions on the exchange, it depends also on the number of investors on the market. The more investors enter the exchange, the smaller is the probability of informed trading leading to a smaller expected spread on the secondary market and hence also to a smaller liquidity risk. Thus there

\footnotetext{
${ }^{12}$ See Hakansson et al. (1993) for a discussion about the necessity of heterogeneous preferences and beliefs for the social value of information.
} 
is a positive externality due to the participation of investors, since an additional investor contributes to reduce the trading cost and to increase the expected utility of all investors.

This participation externality is also driving the results in Dow (2004) who shows that if investors differ in risk aversion, multiple equilibria with different investor participations and levels of liquidity are possible: the more investors enter, the smaller is the spread. Pagano (1989) highlights another participation externality on liquidity: the more investors enter the market, the less the security prices are sensitive to individual endowment shocks.

Entry decision of investors. Investors participate in the IPO if their expected utility from entering the exchange exceeds their opportunity costs: $E U[\tilde{W}]^{*} \geq O c$. Since their individual utility can be concave in the signal precision, $\mathrm{p}$, investors do not necessarily enter on a very transparent market. More generally the following holds for a given level of opportunity costs $(\mathrm{Oc})$.

\section{Lemma 2}

Assume that all investors incur the same opportunity costs.

(i) If the expected utility of investors is increasing in $p$, all investors enter the exchange up from a level of $p$ which equalizes their utility to costs.

(ii) If the expected utility is decreasing in $p$, investors enter the exchange up until the level $\mathrm{p}$ which equalizes their utility to costs.

(iii) If the expected utility is maximized for a $\hat{p} \in[0.5,1]$, there are two threshold levels for the signal precision, $p_{T 1}$ and $p_{T 2}$, with $p_{T 1}<p_{T 2}$ and $p_{T 1}<\hat{p}<p_{T 2}$, such that investors enter if and only if $p \in\left[p_{T 1}, p_{T 2}\right]$.

Investors incur two different utility losses related to information precision. A small precision leads to high trading costs and a small utility. A high precision leads to a high signal risk and possibly also to a small utility. Thus, investors may never enter an opaque as well as a very transparent exchange if they bear opportunity costs.

The concavity in the utility function of investors and the resulting entry behavior is only due to the signal risk. This risk occurs because all investors hold their portfolio unchanged until the signal has been revealed. This kind of risk may seem irrelevant on a financial market on which trading is continuous because investors can always take position before information is released. However, the stock market is also used for long term investments and investors can have different investment horizons. This model considers only investors with a long horizon (implicitly their objective is to wait until the end of the game), 
but who can be hit by an exogenous liquidity shock and thus be forced to sell after information was released.

Since investors bear different opportunity costs, they do not necessarily enter the exchange all together: if investors with low opportunity costs enter it is not necessarily worthy for investors with high opportunity costs to enter the exchange. The entry decision of both investor types depends on the effect of the level of listing requirements on their utility.

\section{Proposition 2}

Assume that the expected utility $E U[\tilde{W}]^{*}$ is maximized for $\hat{p} \in(0.5,1)$. Two outcomes are possible:

(i) The number of high cost investors is high leading to an important participation externality and all investors enter the market as long as the precision is between two thresholds: $p \in\left[p_{T 1}^{\forall}, p_{T 2}^{\forall}\right]$ with $p_{T 1}^{\forall}<\hat{p}<p_{T 2}^{\forall}$.

(ii) The number of high cost investors is small leading to a small participation externality. If the exchange is either opaque or transparent $\left(p \in\left[p_{T 1}^{l}, p_{T 1}^{h}\right]\right.$ and $p \in\left[p_{T 2}^{h}, p_{T 2}^{l}\right]$ with $p_{T 1}^{h}>p_{T 1}^{l}$ and $\left.p_{T 2}^{h}<p_{T 2}^{l}\right)$, only low cost investors enter. For intermediate levels of listing requirements all investors enter the exchange.

Because investors differ in opportunity costs, multiple equilibria are possible. With a low level of listing requirements, investors with high opportunity costs can be deterred from entering the market leading to a set of equilibria with small investor participation and a small liquidity. The higher the level of listing requirements is, the smaller is the spread which increases the expected utility of all investors (provided that their signal risk is small) and attracts, up from a particular level, investors with high opportunity costs on the exchange. Thus, a higher level of listing requirements leads to a set of equilibria with high investor participation and a good liquidity. In this case, the spread is small not only because the listing requirement reduces information asymmetry, but also because the high number of participating uninformed investors reduces the probability of informed trading. However, as soon as a higher precision decreases the individual utility of investors, investor participation becomes smaller since high cost investors do not enter the exchange for levels of $\mathrm{p}$ up from the threshold $p_{T 2}^{h}$. In this case, more precise public information has an ambiguous effect on the liquidity. On the one hand, the market maker can assess more accurately the expected payoff of the security which reduces the spread. On the other hand, the number of uninformed investors becomes smaller which increases informed trading and thus also the spread. If the number of high cost uninformed investors is high, very precise public information may deteriorate liquidity because only a small number if uninformed investors enter the exchange. 
The threshold level of $\mathrm{p}$, at which high cost investors enter, is smaller with the participation externality, than it would be without. Whether such an externality leads to a single set of equilibria depends on its magnitude, which in turn depends on the number of high cost investors in the economy $\left(N_{h}\right)$. If their number is high, the effect of their entry on their utility is so high that it is always worthy for them to enter. In this case, there is a unique set of equilibria in which all uninformed investors enter. Otherwise, multiple sets of equilibria exist.

\section{Optimal organization of the exchange}

Trading fee. The exchange sets the trading fee to maximize its income from trading and listing. The trading fee has opposite effects on the exchange's profit. It increases the income per traded share but reduces the number of shares issued and therefore the volume. Since a higher trading fee reduces the utility of investors, it can also lead to a small market participation reducing further the volume. The market capitalization of the firm decreases also the higher the trading fee is, because the price investors are willing to pay diminishes in addition to the smaller number of issued shares.

The volume the exchange expects depends not only on the number of shares, but also on the probability with which uninformed investors trade. If the firm is bad, informed investors always mimic uninformed ones and volume always occurs. If, however, the firm is a good one, informed investors never trade and the volume depends on the probability with which uninformed investors are hit by a liquidity shock, t. In the third stage, the probability of trading is: $0.5(1+t)$. The optimal trading fee is determined by the following maximization problem:

$$
\underset{c}{\operatorname{Max}} \Pi(c)=0.5(1+t) K^{*} c+K^{*} P_{I P O}^{*}-C(p)
$$

The first term represents the income from trading, the second term represents the income from the listing fee and the last term is the regulatory cost (which does not depend on the trading fee). The trading fee maximizing the profit of the exchange is:

$$
c_{N_{u}}^{*}=(1-t) \frac{E[V]-t S_{N_{u}} / 2}{2 t}
$$


The trading fee set in equilibrium increases the higher the precision of the signal is as long as a higher $\mathrm{p}$ entails market participation. A higher precision leads to a smaller spread due to less informed trading and possibly more market participation. The smaller spread reduces the trading costs and the horizon risk of investors. Both effects translate into a smaller cost of capital for the firm, which issues more shares. This in turn increases the volume as well as the income from listing. In equilibrium, the exchange exploits this mechanism to increase its trading fee. If all investors are on the market, the increase in the trading fee with the precision is weaker than in the case in which only low cost investors enter. This is because the higher number of uninformed investors reduces the sensitivity of the spread to changes in $\mathrm{p}$. In the specific case in which high cost investors do not enter for high levels of $\mathrm{p}$, increasing p has an ambiguous effect on the spread and therefore also on the trading fee. Although the trading fee increases almost always in p, the total trading costs decrease with a more precise the signal. ${ }^{13}$ The exchange never increases the optimal trading fee to offset completely the smaller spread.

The optimal trading fee decreases the higher the probability of a liquidity shock, $t$, is. The more likely investors are to sell their holding on the secondary market, the smaller is the probability of informed trading and thus the spread, but the more the utility of investors is sensitive to trading costs and the higher is their signal risk. These effects can reduce the number of issued shares and thereby the volume and the income from listing. To reduce the negative effects of a higher $t$, the exchange diminishes its trading fee.

Since a higher trading fee reduces the income from listing, a monopoly exchange offering both services, listing and trading, sets a smaller trading fee than a monopolist exchange which organizes only trading. ${ }^{14}$ The utility of investors increases the smaller the trading fee is because the trading cost and the horizon risk diminish. Thus, although with a listing fee, the surplus of firms is zero, investors are better off than if the exchange does not charge a listing fee because the trading fee is smaller. The smaller trading fee can also lead to a higher market capitalization and a higher volume. An monopoly exchange with income from listing as well as trading is larger with respect to both, volume and market capitalization, than an exchange with income only from trading.

\footnotetext{
${ }^{13}$ Total expected trading costs are: $t\left(\frac{S}{2}+c^{*}\right)=\frac{E(V)}{2}(1-t)+t(1+t) \frac{S}{4}=T C$. It follows that $\frac{\partial T C}{\partial p}=\frac{t}{4}(1+t) \frac{\partial E(S)}{\partial p}<0$

${ }^{14}$ The trading fee without income from listing is: $c_{N_{u}}^{*}=\left(E[V]-t S_{N_{u}} / 2\right) / 2 t$
} 
Listing requirements. Once the trading fee is chosen, the exchange sets the level of listing requirements to maximize its profit. At this stage, its profit depends on the spread, on the number of uninformed investors on the exchange, and on the risk premium required by investors. These three elements affect the utility of investors and determine therefore the volume and the market capitalization. The exchange maximizes its profit to determine the optimal precision. Its profit is:

$$
\Pi(p)=\frac{(1+t)^{2} N_{u}(p)}{t} \frac{\left(E[V]-t \frac{S(p)}{2}\right)^{2}}{16 b((1-t) \operatorname{Var}(V)+t \operatorname{Var}(P)+L R)}-C(p)
$$

An increase in $\mathrm{p}$ has two positive effects on the profit through the spread and the number of investors, and two negative effects through the signal risk and the regulatory costs. A higher precision reduces the spread and thereby the trading costs as well as the horizon risk. This increases the profit of the exchange. A higher precision can also lead to higher market participation (see proposition 2). More investor participation increases the number of issued shares which in turn leads to a higher listing fee and volume. However, the more investors enter the exchange, the less sensitive is the spread to changes in $p$ which reduces the gain of an increase in $\mathrm{p}$ for the exchange. Finally, a higher precision increases the signal risk which reduces the profit of the exchange. The last effect makes the income of the exchange concave in $\mathrm{p}$, similarly to the utility of investors.

The equilibrium level of listing requirements depends on several parameters. The higher the number of uninformed investors on the market is, the higher is the optimal precision (assuming that a marginal increase in $\mathrm{p}$ is not the source of the higher number of uninformed investors). High market participation not only increases the volume and the market capitalization directly, but it also contributes to reduce the spread and leads thus to smaller trading costs and to a smaller risk premium. This lowers the negative effect of a higher precision on the utility of investors through the signal risk, and induces therefore the exchange to set a high precision in equilibrium. Thus, if the exchange attracts only low cost investors on the market, the level of listing is always smaller than if all uninformed investors enter the exchange in equilibrium. The exchange never implements an equilibrium with a high transparency and small investor participation.

The fundamental risk of the firm which increases with the difference in productivities, $\left(\bar{x}^{h}-\bar{x}^{l}\right)$, and the risk of the undertaken project, $\sigma$, reduce the importance of changes in the precision on the trading costs and the horizon risk. Therefore, the more risky the firm is, the 
lower is the equilibrium precision. However, while the risk of the project only affects the fundamental risk, a higher difference in productivities also increases the spread. Thus diverging average productivities lead to higher trading costs and reduce further the equilibrium level of listing requirements. The effect of the economic risk is smaller the more likely a liquidity shock is. In this case, however, investors' utility becomes more sensitive to changes in the spread which amplifies the effect of diverging productivities. Thus, an exchange is particularly likely to set a low level of listing requirements if the qualities of the listed firms are highly different

Given an optimal level of listing requirements set by the exchange, the expected utility of investors is the following:

$$
U\left(p^{*}, c^{*}\right)=(1+t)^{2} \frac{\left(E[V]-t \frac{S}{2}\right)^{2}}{32 b((1-t) \operatorname{Var}(V)+t \operatorname{Var}(P)+L R)}+W_{0}
$$

Since the volume and the market capitalization depend on the number of issued shares which are determined by the trading costs and the risk premium required by investors, the factors affecting the profit of the exchange are the same as those affecting the utility of investors. Listing requirements are considered as a device to improve investor protection. Thus, they should increase the utility investors obtain from entering the stock market. To compare the equilibrium level of listing requirements set by a profit maximizing exchange with the one maximizing investor welfare, define the sum of investors' utilities as the investor welfare function, Iw:

$$
I w=\sum_{N_{u}} E U[\tilde{W}]^{*}
$$

The utility of investors is concave in p. According to proposition 1, the utility can also decrease for high levels of $\mathrm{p}$. Therefore, investor welfare is also concave and can also be decreasing in $\mathrm{p}$. If the aggregated utility is increasing in $\mathrm{p}$ for $p \in(0.5,1)$, the optimal precision from the point of view of investors is perfectly informative: $p=1$. However, the higher the precision is, the smaller is the utility gain of investors. If the aggregated utility of investors decreases for high precision, the level of $\mathrm{p}$ maximizing investor welfare is $\hat{p}$ such 
that $\partial I w / \partial p=0$. If the information risk is an important component of the utility function, investors are best off with a noisy signal $(\hat{p}<1)$.

\section{Proposition 3}

Assume that the income of the exchange and the individual utility of investors are maximized at $\hat{p}$, and that all investors incur the same opportunity costs:

(i) Without regulatory costs, the exchange sets the level of listing requirements maximizing investors' welfare in equilibrium.

(ii) If there are regulatory costs, the exchange under-regulates and sets a smaller precision than the one maximizing investor welfare in equilibrium.

Although the exchange's income is more sensitive to changes in $p$ than the utility of investors, both are maximized at the same precision. Thus, because the activity on the exchange and consequently its income are determined by the preferences of investors, a monopolist exchange always sets the level of listing requirements maximizing investor welfare if this is costless. If, however, the regulatory activity is costly and the exchange bears the costs, the exchange sets always a too low level of listing requirements from the point of view of investors. Under-regulation is uniquely due to the existence of costs, but the extent of under-regulation is also determined by the sensitivity of the exchange's income with respect to changes in p. For a given cost function, the more sensitive the exchange's income is to changes in the precision, the higher is the optimal level of listing requirements and the less the exchange under-regulates.

If the individual utility of investors and the income of the exchange are increasing in $p$, the exchange sets always the highest level of listing requirements if regulatory costs are small, in which case, the solution is also socially optimal. With high regulatory costs, the exchange under-regulates. If both functions are decreasing, the exchange sets the smallest level of listing requirements regardless of the cost function. This is also the socially optimal solution.

The result in proposition 3 is consistent with Chemmanur and Fulghieri (2006) and Huddart et al. (1999) in the sense that the exchange tends to set a high level of listing requirements to maximize its profit. In both mentioned papers, the authors demonstrate that an exchange which is a monopoly as well in listings as in trading sets high listing requirements, although the mechanisms through which this result is obtained are quite different. Chemmanur and Fulghieri (2006) only consider the listing decisions of firms and conclude that an exchange has the incentive to set a high level of listing requirements to keep a good reputation. Huddart et al. (1999) argue that liquidity volume tends to gather on the more transparent market on which there is a smaller risk of adverse selection. However, in these 
two papers the monopoly exchange always set the highest possible level of listing requirements. Proposition 3 nuances this result since investor welfare is not necessarily increasing in the precision of information which affects the expected trading volume in equilibrium. The exchange does not necessarily maximize its profit with the highest level of precision even without regulatory costs. Thus the signal risk stemming from the commitment of the listed firm to disclose information affects the optimal decisions of the exchange indirectly through the demand of investors and can in particular preclude the corner solution of perfect information revelation (the highest possible level of listing requirements in this model).

\section{Lemma 3}

Equilibria in which all uninformed investors participate lead always to a higher investor welfare and dominate therefore equilibira in which only low cost investors enter. If investors differ in opportunity costs, the level of listing requirements maximizing investor welfare is always in the interval: $\left[p_{T 1}^{h}, p_{T 2}^{h}\right]$

A higher number of uninformed investors improves always liquidity. Regardless of the level of listing requirements, the market maker sets a smaller spread in the case all investors enter the exchange. This reduces not only the total trading costs but diminishes also the liquidity risk. The equilibrium with the highest market participation has also the highest level of listing requirements. Since investors do not bear costs associated with the production of the public information, this equilibrium always maximizes the aggregated expected utility of investors.

The income of the exchange is affected by the same effects and increases therefore the higher the number of participating investors is. However, the exchange also bears regulatory costs which increase with the precision. Since the equilibrium in which investor participation is the highest is also the one with the highest precision, it is only optimal for the exchange if the difference in costs is small relative to the difference in income. The difference in income increases the higher the expected quality of the firm is since this amplifies the difference in the expected spread. The effect of the risk of the firm's economic activity and the signal risk on the difference in income is ambiguous. A higher difference in average qualities, increases not only the fundamental risk and the signal risk, but makes the expected spread more sensitive to changes in the number of participating investors. The more risky the economic activity of the firm is and the higher uncertainty on the quality of firms is, the less likely it is that the exchange implements the equilibrium with a high investor participation. 


\section{Proposition 4}

If investors differ in opportunity costs and multiple equilibria exist, two outcomes are possible in equilibrium:

(i) The exchange implements the equilibrium with a high investor participation. If there are regulatory costs, it under-regulates.

(ii) The exchange implements the equilibrium with a small investor participation. In this case the exchange always under-regulates.

If investors differ in opportunity costs, the level of listing requirements determines the number of investors entering the exchange. In this case the exchange may set a too low level of listing requirements if its cost function is steep. But this may occur for two reasons: either the equilibrium with a high investor participation is implemented but costs are such that the level of listing requirements maximizing the exchange's profit is smaller than the one maximizing welfare. However, even with a nearly flat cost function the exchange may optimally implement the equilibrium with a small investor participation, in which case welfare is never optimized since all high cost investors do not enter the exchange and fall back on their alternative investment opportunity. Thus, if the income of the exchange is not sensitive enough to changes in the level of the precision, the exchange always sets a too small level of listing requirements regardless of the shape of the cost function.

When the level of listing requirements influences investor participation, the exchange is even more incited to under-regulate and this incentive is not necessarily linked to the steepness of its cost function. Indeed, the exchange only implements the equilibrium in which many investors enter if the obtained difference in liquidity allows the exchange a high enough increase in its income through higher trading and listing fees. Thus, if liquidity is not sensitive enough to changes in the number of investors, or if a high risk of the economic activity of the firm reduces the importance of changes in the spread in the utility of investors, the exchange always under-regulates from the point of view of investors. The existence of multiple equilibria related to the level of listing requirements complements further the results in Chemmanur and Fulghieri (2006) and Huddart et al. (1999) since it may be optimal for the exchange to exclude investors by setting a small level of listing requirements if liquidity is not responsive enough to changes in the precision and participation.

\section{Separation of listing and trading}

In the previous sections, the exchange is a monopolist in listing and trading. Results have shown that although investors can benefit from higher listing requirements through a 
smaller spread, the increase in their utility is small because the exchange is induced to increase its trading fee with $\mathrm{p}$. Also, the exchange under-regulates if there are regulatory costs and if its income does not increase enough with $\mathrm{p}$.

While listings are often done on home exchanges (foreign listings concern a rather small group of firms in the world), there are many alternative trading venues that appear and which compete for trading volume with "traditional" exchanges. If a trading platform emerges and offers to trade the securities of listed firms at a lower trading fee, it benefits from the certification role played by listing requirements without bearing the regulatory costs. Thus, listing requirements become a public good. As the exchange risks losing its volume on the secondary market, it may be induced to lower the level of listing requirements. Indeed, the exchange does not internalize the whole benefits related to them but bears the complete regulatory costs.

To analyze how this development influences the decisions of an exchange regulating listings as well as the welfare of investors, an extreme case is considered in which the listing function is separated from the trading function. An exchange is monopolist in listings (further on "the exchange") whereas other trading venues have the complete trading volume (further on "trading platforms"). Several authors claim that the stock market industry should specialize on offering a cheap and liquid trading venue and leave the regulatory activity concerning listings to other institutions. Self regulating exchanges seem not to be in the majority and listings are at least partially regulated by other institutions (Macey and O'Hara 2005). The setting considered here corresponds to a situation in which listings are regulated by a profit maximizing entity which is a monopoly in this activity. It is called "exchange" for continuity with the previous sections, but corresponds to the concept of "listing agency" in Steil (2002).

As in the previous sections, the determinants of the exchange's profit as well as the investors' welfare are analyzed and optimal listing requirements compared. As described in the monopoly case, the trading fee has an impact on the market value of the listed firm and thus on the income from listing and eventually the decision upon the level of listing requirements. The interdependence between trading fee and optimal precision remains in the case of separation of trading from listing, since the market value of the firm which corresponds to the listing fee is also determined by the trading fee prevailing on the trading venues used by investors. The industrial organization of trading influences the prevailing trading fees: these are independent from the level of information precision set by the listing exchange and small in case of strong competition, whereas they are likely to be high in the 
absence of competition. Thus, the industrial organization of the trading industry influences the decision of the exchange upon listing requirements. To assess how different organizations of the trading industry affect investor welfare and possible under-regulation, two cases are considered: the coexistence of a monopolist exchange which lists firms and a monopolist trading platform, and the coexistence of a monopolist in listing and a competitive trading industry.

Two monopolists. The trading platform sets the trading fee to maximize its income from trading. The trading venue does not bear costs since it does not regulate listings. In this case, the optimal trading fee depends on the precision set by the exchange. As in the previous sections, the trading platform increases its fee the higher the level of listing requirements is to exploit the smaller spread. In equilibrium, the platform charges a higher trading fee than the one set by the single exchange in section 4, because the platform does not internalize the negative effect of the trading fee on the market capitalization and thus on the listing fee. The equilibrium trading fee is given in footnote 16 (see section 4).

The exchange sets the precision, $\mathrm{p}$, to maximize its profit from listing. It takes into account the trading fee set by the trading platform. The profit of the exchange is smaller than in the previous sections since the trading income has disappeared and the trading fee is higher:

$$
\Pi(p)=\frac{N_{u}(p)\left(E[V]-t \frac{S(p)}{2}\right)^{2}}{16 b((1-t) \operatorname{Var}(V)+t \operatorname{Var}(P)+L R)}-C(p)
$$

The income from listing is lowered and less sensitive to changes in $\mathrm{p}$. Therefore, the optimal level of listing requirements is smaller than it was in the case of a single exchange. The trading platform benefits from the listing requirements set by the listing exchange since they affect the spread. Therefore, the trading fee is a function of the level of listing requirements satisfied by the listed firm. The higher the level of listing requirements is, the higher is the number of issued shares and the higher is the optimal trading fee of the platform. The platform would like the listing exchange to set a high precision. However, because the exchange does not internalize the profit of the trading platform and is disadvantaged due to the high trading fee, it does not set a high level of listing requirements in equilibrium. Since the negative impact of the higher trading fee on the listing fee is not taken into account by the 
trading platform, the trading fee is higher and the listing requirement smaller compared to the case of a single exchange.

\section{Proposition 5}

If there are two coexisting monopolies, one in trading and one in listing:

(i) Investor welfare is smaller than in the case of a single exchange offering both services simultaneously.

(ii) Compared to the new optimal level of listing requirements of investors, the listing exchange only under-regulates if there are regulatory costs.

Investors are worse off when two monopolies, one in trading and one in listing, coexist because the trading costs are higher. The exchange's income depends on the size of the issue which is determined by the preferences of investors. Therefore the exchange never sets the precision at a level at which the higher signal risk over-compensates the gain from a better market liquidity. The income of a single exchange offering listing as well as trading is more sensitive to changes in the precision than the income of an exchange which lists only firms. Therefore, even with equal trading fees, the level of listing requirements is always smaller in the case of separation than in the case of a single exchange. This is the first reason for the smaller utility. The second reason is the higher trading fee set by the trading platform which increases not only the costs of investors if they trade, but contributes to reduce further the listing requirements set by the exchange.

The individual utility of investors changes compared to the case of a single exchange. For any level of $p$, the higher level of trading costs decreases the sensitivity of the utility to changes in the spread. Since a higher precision has a positive effect on the utility through a smaller spread, but a negative effect due to the higher signal risk, the precision maximizing investor welfare is smaller than in the case of a single exchange. Changes in the industry of listing and trading affect the optimal level of listing requirements from the point of view of investors, because these changes affect the trading fee which in turn determines the listing requirements set by the exchange. If the exchange bears regulatory costs, it under-regulates. Under-regulation is more severe (for a given number of investors in the exchange) than in the case of a single exchange because the income from listing is less sensitive to changes in the precision. This is not only because the exchange forgoes the profit from trading, but also because the trading platform does not internalize the negative effect of the trading fee on the profit of the exchange. As a result, in the case of a single exchange which is a monopolist in listing as well as in trading, investors are better off and under-regulation is less severe than in 
the case there is separation of listing and trading, but two monopolies control each activity respectively.

Monopoly in listing and competition in trading. The lower investor welfare and the more severe under-regulation in the case of two coexisting monopolies were due to the interdependence between the trading fee and the listing requirements. This interdependence also contributes to lower investor welfare in the case of one single exchange. One way to improve social welfare and to mitigate the under-regulation problem, is to increase the sensitivity of the utility of investors and of the profit of the exchange, to the liquidity effects induced by listing requirements. This is possible if the trading fee is decoupled from the listing requirements and if it is small, which is the case if the trading industry is competitive. In the absence of costs related to the functioning of trading venues (implicitly assumed here), the trading fee is zero.

A zero trading fee increases the amount of issued shares and the market capitalization of the listed firms. This increase the income the exchange obtains from listing. Since there is no income related to trading, the free riding problem does not exist anymore. The exchange sets the listing requirements to maximize its profit from listing, which is the only possible profit in the economy:

$$
\Pi(p)=\frac{N_{u}(p)\left(E[V]-t \frac{S(p)}{2}\right)^{2}}{4 b((1-t) \operatorname{Var}(V)+t \operatorname{Var}(P)+L R)}-C(p)
$$

The profit of the exchange is smaller than the profit in the case of a single exchange (see equation 14). The higher income from listings does not offset the absence of income from trading. Moving from an industry in which a monopolist exchange lists firms and trades the shares to an industry in which both functions are separated and in which the trading industry is competitive reduces the profit of the exchange. However, the exchange's income is four times higher than if trading is also operated by a monopoly because the trading fee is smaller. Consequently, the precision set by the exchange in equilibrium is smaller than if it is a single exchange but higher than if there is a monopolist trading venue.

\section{Proposition 6}

If there is a monopoly in listing but a competitive trading industry 
(i) Investor welfare is higher than in the case of two monopolies and than in the case of a single exchange listing firms and trading shares.

(ii) Under-regulation still exists if the exchange bears regulatory costs

Investors benefit not only from a small (or zero) trading fee, they also benefit more from increases in the spread. Since the exchange sets a higher precision, the utility of investors increases. The absence of a trading fee which leads to the higher sensitivity to the positive liquidity effects of listing requirements, increases the utility above its levels (for any p) in the case of a single exchange. While the exchange loses income as soon as listing is separated from trading, investors gain form separation if the trading industry is competitive.

Since investor welfare is the highest compared to the two previous cases, the optimal precision from the point of view of investors is also higher than in all cases considered previously. If the exchange does not bear regulatory costs it sets the socially optimal level of listing requirements. If the exchange bears regulatory costs, under-regulation is more severe than in the case of a single exchange because the sensitivity of the exchange's profit to changes in the precision is smaller than if the exchange is a monopoly in trading and listing. However, under-regulation is less severe than in the case of coexistence of two monopolies.

To sum up, investor welfare is the highest when listing is separated from trading and the trading industry is competitive. It is the lowest if there is separation but two monopolies coexist, and intermediate if a single exchange lists firms and organizes trading. Consequently the socially optimal level of listing requirements is the highest when trading is competitive and separated from listing. However, the exchange sets the highest level of listing requirements when it is a single monopoly. The under-regulation problem is more severe when there is no income from trading in the economy. The number of uninformed investors can contribute to mitigate the under-regulation problem. The higher the number of investors on the exchange is, the higher is the sensitivity of the exchange's income to changes in the precision. Thus, in the case all investors participate on the exchange, the under-regulation problem is less severe in all cases, than if only low cost investors enter. The higher the number of investors is, the less sensitive the spread is to changes in $\mathrm{p}$ and the smaller is the socially optimal precision in all cases. Because investors require a smaller precision and the exchange is induced to set a higher precision, a higher number of investors mitigates the under-regulation problem. 


\section{Conclusion}

I propose a model in which a stock exchange can improve its liquidity by tightening its listing requirements. Because these reduce information asymmetry, they increase the utility of investors and lead to a high investor participation on the exchange. However, the exchange never sets the highest possible level of listing requirements because investors also incur a risk due to more transparency. Their utility is concave in the level of listing requirements. This property determines the optimal decisions of an exchange as well as the social optimum. The level of listing requirements maximizing investor welfare depends on the sensitivity of the utility of investors to changes in liquidity and varies with the organization of listing and trading. A monopolist exchange always under-regulates if regulation is costly. Underregulation is exacerbated if other trading venues free ride on the regulation and if the trading fee is determined by the level of listing requirements. While investors are better off if trading is separated from listing and is a competitive industry, an exchange has a higher profit when it is a monopolist in listing and trading.

\section{Appendix}

\section{Lemma 1}

Follows directly form the variance of investors' final wealth:

$$
\begin{aligned}
& \operatorname{Var}(\tilde{W})=D^{2}\left((1-t) \frac{1}{4}\left(\Delta x^{2}+4 \sigma^{2}\right)+t \frac{1}{4}(1-2 p)^{2}\left(\bar{x}_{h}-\bar{x}_{l}\right)^{2}+\left(\frac{S}{2}+c\right)^{2}(1-t) t\right) \\
& =D^{2}((1-t) \operatorname{Var}(V)+t \operatorname{Var}(P)+L R)
\end{aligned}
$$

\section{Lemma 2: Investors' entry}

Three cases must be considered:

If $\frac{\partial E U[\tilde{W}]^{*}}{\partial p}>0$ for $p \in(0.5,1)$, investors enter the exchange for $p>p_{T^{\prime}}$ with $E U\left[\tilde{W}\left(p_{T^{\prime}}\right)\right]^{*}=O c$. If $\frac{\partial E U[\tilde{W}]^{*}}{\partial p}<0$ for $p \in(0.5,1)$, investors enter the exchange for $p<p_{T^{n}}$. If $E U[\tilde{W}]^{*}$ is maximized at $p_{E U}^{*}$, investors enter for $p \in\left[p_{T 1}, p_{T 2}\right]$ with $E U\left[\tilde{W}\left(p_{T 1}\right)\right]^{*}=E U\left[\tilde{W}\left(p_{T 2}\right)\right]^{*}=O c$.

\section{Proposition 1: Concave utility}

$\frac{\partial E U[\tilde{W}]^{*}}{\partial p}=0$ if and only if the following condition holds: $P_{I P O}^{*}=2 A$, which is true for $p_{E U}^{*}$. $E U[\tilde{W}]^{*}$ increases in $\mathrm{p}$ if $P_{I P O}^{*}<2 A$ and decreases in $\mathrm{p}$ otherwise. Since $\frac{\partial P_{I P O}^{*}}{\partial p}>0$ and 
$\frac{\partial A}{\partial p}<0, E U[\tilde{W}]^{*}$ increases for $p<p_{E U}^{*}$ and decreases for $p>p_{E U}^{*}$. Therefore, the expected utility is concave in p. If $p_{E U}^{*}<0.5$, the utility of investors always decreases with $\mathrm{p}$. If $p_{E U}^{*}>1$, the utility increases with $\mathrm{p}$. If $p_{E U}^{*} \in(0.5,1)$, the utility is maximized at $p_{E U}^{*}$.

$A=((1-t) \operatorname{Var}(V)+t \operatorname{Var}(P)+L R)\left(\frac{4 \Delta x}{1-(1-n) t}-2(1-t)\right)^{-1}$

\section{Proposition 2: entry with different opportunity costs:}

If $N_{h}$ is high, all investors enter for $\mathrm{p}$ between $p_{T 1}^{\forall}$ and $p_{T 2}^{\forall}$ with $E U\left[\tilde{W}\left(p_{T 1}^{\forall}\right)\right]^{*}=E U\left[\tilde{W}\left(p_{T 2}^{\forall}\right)\right]^{*}=O c_{h}$. If $N_{h}$ is small, low cost investors enter for $\mathrm{p}$ between $p_{T 1}^{l}$ and $p_{T 2}^{l}$ with $E U\left[\tilde{W}\left(p_{T 1}^{l}\right)\right]^{*}=E U\left[\tilde{W}\left(p_{T 2}^{l}\right)\right]^{*}=O c_{l}$. High cost investors enter for $\mathrm{p}$ between $p_{T 1}^{h}$ and $p_{T 2}^{h}$ with $E U\left[\tilde{W}\left(p_{T 1}^{h}\right)\right]^{*}=E U\left[\tilde{W}\left(p_{T 2}^{h}\right)\right]^{*}=O c_{h}$.

\section{Proposition 3: private and social optimum for equal opportunity costs}

In equilibrium investors welfare is:

$$
I w=N_{u} E U[\tilde{W}]^{*}=N_{u}\left[W_{0}+\frac{(E(V)-t S / 2)^{2}}{32 b\left((1-t) \operatorname{Var}(V)+t \operatorname{Var}(P)+L R\left(c^{*}\right)\right)}\right]=N_{u}\left[W_{0}+\frac{1}{32 b} B\right]
$$

It follows: $\frac{\partial I w}{\partial p}=\frac{N_{u}}{32 b} \frac{\partial B}{\partial p}$. The expected equilibrium profit is:

$E(\Pi) *=\frac{N_{u}}{8 b}\left(E(V)-t \frac{S}{2}\right)^{2}((1-t) \operatorname{Var}(V)+t \operatorname{Var}(P)+L R)^{-1}-C(p)=\frac{N_{u}}{8 b} B-C(p)$. It follows:

$\frac{\partial E(\Pi)^{*}}{\partial p}=\frac{N_{u}}{8 b} \frac{\partial B}{\partial p}-\frac{\partial C}{\partial p}$. Assuming the welfare is maximized at $p_{E U}^{*}$, the optimal precision

for investors is such that $\frac{\partial B}{\partial p}=0$. If the exchange bears regulatory costs, its optimal precision is such that $\frac{\partial E(\Pi)^{*}}{\partial p}=\frac{N_{u}}{8 b} \frac{\partial B}{\partial p}-\frac{\partial C}{\partial p}=0$, which is always a lower level than the one maximizing investor welfare.

\section{Lemma 3}

$N_{l}\left[W_{0}+\frac{1}{32 b} B\left(N_{l}\right)\right]>N_{l+h}\left[W_{0}+\frac{1}{32 b} B\left(N_{l+h}\right)\right]$ since the expected spread and the liquidity risk are smaller the more investors enter the exchange

\section{Proposition 4}

If $\frac{1}{8 b}\left[N_{l+h} B\left(N_{l+h}\right)-N_{l} B\left(N_{l}\right)\right]>C\left(p_{l+h}^{*}\right)-C\left(p_{l}^{*}\right)$, the exchange implements the equilibrium in which all investors enter. See proposition 3. Otherwise, the exchange implements the equilibrium in which only low cost investors enter. Since the optimal listing requirement is always smaller than for the other equilibrium, it is always sub-optimal (see Lemma 3). 


\section{Proposition 5}

With two coexisting monopolies, B (see proposition 3 ) is smaller than in the case of a single exchange. It follows that investor welfare is also smaller.

Since only B changes, the under-regulation problem is as in proposition 3.

\section{Proposition 6}

$(1+t)^{2}<4$. Individual utilities are larger than in the two other cases. Therefore, investor welfare is also the largest. The under-regulation problem is as in proposition 3.

\section{References}

Alles M., R. Lundholm, 1993. On the optimality of public signals in the presence of private information. Accounting review 68, 93-112

Centre for financial market integrity, 2007: "Self-regulation in today’s securities markets"

Chavez G. and C. Silva, 2006. Improved corporate governance: market reaction and liquidity implications

Chemmanur T., P. Fulghieri, 2006. Competition and co-operation among exchanges: a theory of cross-listing and endogenous listing standards. Journal of Financial Economics 82, 455 489

Christiansen C., J. Joensen and J. Rangvid, 2005. Do more economists hold stock? Working Paper

Coffee J., 2002. Racing towards the top? The impact of cross-listings and stock market competition on international corporate governance. Columbia Law Review 102, 1757 - 1831

Diamond D., 1985. Optimal release of information by firms. Journal of finance 40, 1071-1094

Doidge C., A. Karolyi, R. Stulz, 2004. Why are foreign firms listed in the US worth more? Journal of Financial Economics 71, $205-238$

Dow J., 2004. Is liquidity self-fulfilling? Journal of business 77, 895 - 908

Easley D., M. O’Hara, 2007. Microstructure and ambiguity. Working Paper

Fleckner A., 2006. Stock exchanges at the crossroads. Fordham Law Review 74, 2541 - 2620

Fuerst O., 1998. A theoretical analysis of the investor protection regulations argument for global listing of stocks. Working Paper

Goldstein M., A. Shkilko, B. van Ness, R. van Ness, 2007. Competition in the market for NASDAQ securities. Forthcoming, Journal of financial markets 
Guiso L., P. Sapienza and L. Zingales, 2008. Trusting the stock market. Journal of finance 63, $2557-2600$

Hakansson H., J. Kunkel, J. Ohlson, 1982. Sufficient and necessary conditions for information to have social value in pure exchange. Journal of finance $37,1169-1181$

Hirshleiffer J., 1971. The private and social value of information and the reward to inventive activity. American economic review 61, 561-574

Huddart S., J. Hughes, M. Brunnermeier, 1999. Disclosure requirements and stock exchange listing choice in an international context. Journal of Accounting and Economics 26, 237 - 269

Jain P., J. Kim and Z. Rezaee, 2006. Trends and determinants of the market liqudity in the pre- and post- Sarbanes-Oxley Act periods. Working Paper

Jenkinson T., T. Ramadorai, 2007. Do investors value high levels of regulation? Working paper

Kuan J. and Diamond S, 2006. Ringing the bell on the NYSE: might a nonprofit stock exchange have been efficient? Santa Clara University School of Law, working Paper

Lee R., 2002. The future of securities exchanges. Wharton financial institutions centre, working paper

Leuz C., 2004. Prorpietary versus non proprietory disclosures: evidence from Germany. Oxford University Press 2004

Macey J., M. O'Hara, 2002. The economics of stock exchange listing fees and listing requirements. Journal of Financial Intermediation 11, 297 - 319

Macey R. and M. O'Hara, 2005. From markets to venues: securities regulation in an evolving world. Stanford Law Review 58, 563 - 599

Nguyen T., B. van Ness and R. van Ness, 2005. Archipelago's move towards exchange status: an analysis of archipelago trading in NYSE and NASDAQ stocks. Working Paper

Nichols N. and D. Street, 2007. The relationship between competition and business segment reporting decisions under the management approach of IAS 14 revised. Journal of international accounting, auditing and taxation 16, $51-68$

OICV - IOSCO Consultation Report 2006: Regulatory issues arising from exchange evolution.

Pagano M., 1989. Endogenous market thinness and stock price volatility. Review of financial studies 56, $269-287$

Steil B., 2002. Changes in the ownership and governance of securities exchanges: causes and consequences. Brookings-Wharton papers on financial services 
Stoll H., 2006. Electronic trading in stock markets. Journal of economic perspectives 20, 153 $-174$

Stoughton N., K. Wong, J. Zechner, 2001. IPOs and product quality. Journal of Business 74, $375-408$

Verrecchia R., 1983. Discretionary disclosure. Journal of accounting and economics 5, 179 194

Verrecchia R., 2001. Essays on disclosure. Journal of accounting and economics 32, 97 - 180 